\title{
The apoptosis pathway of photodynamic therapy using 9-HpbD-a in AMC-HN3 human head and neck cancer cell line and in vivo
}

\author{
Jin-Chul Ahn \\ Medical Laser Research Center, Dankook University, 29-1, Anseo-dong, Cheonan, Chungnam, Korea
}

\begin{abstract}
Hydroxypheophorbide-a (9-HpbD-a), a new photosensitizer was extracted from the green alga Spirulina platensis. The anticancer effects of photodynamic therapy (PDT) treatment using 9-HpbD-a against human head and neck cancer cell HN3 and in vivo mice model were investigated. Cells were incubated with 9-HpbD-a for at least 6 hours or more followed by the laser irradiation. Cytotoxicity of 9-HpbD-a against HN3 cell was determined using the MTT assay, propidium iodide and Hoechst 33342 staining and transmission electron microscopy (TEM). To determine the mechanism of cell death, Western blot analysis was performed. The antitumor effect was confirmed in a cancer cell xenograft nude mouse model by photodynamic therapy (PDT) using 9-HpbD-a. For normal control and the 9-HpbD-a only treated group, tumor tissues showed continuous tumor growth $(100 \%)$. For laser only treated experimental group, 3 treatments showed no remission (75.0\%), and was one recurrence $(25.0 \%)$. Out of 16 tumors in the fourth group of photodynamic treatment, 10 cured (62.5\%), 4 recurrence (25.0\%), and 2 did not heal (12.5\%) were confirmed. PDT using a 9-HpbD-a and $665 \mathrm{~nm}$ diode laser showed significant antitumor effects. Thus PDT using 9-HpbD-a can be a useful new treatment method in the treatment of cancer in the future.
\end{abstract}

Key words: Photodynamic therapy - Photosensitizer - 9-Hydroxypheophorbide-a - Cell death mechanism - Apoptosis

Abbreviations: 9-HpbD-a, 9-hydroxypheophorbide-a; MTT, 3-(4,5-dimethylthiazol-2-yl)-2,5diphenyltetrazolium bromide; PDT, photodynamic therapy; PI, propidium iodide; ROS, reactive oxygen species.

\section{Introduction}

Photodynamic therapy (PDT) is a treatment for the selective destruction of cancerous cells that involves the simultaneous presence of light, oxygen and light sensitive chemicals, photosensitizer which can be localized in the target cells (Dougherty et al. 1978). In recent days, PDT using this photosensitizer or photosensitizing agent and a visible light of a specific wavelength has become a new modality for cancer treatment (Carl 2000). In PDT, photosensitizer is administered to the patient, and after a certain period of time it is accumulated in the tumor cells and excited by laser

Correspondence to: Jin-Chul Ahn, Medical Laser Research Center, College of Medicine, Dankook University, 29-1, Anseo-dong, Cheonan, Chungnam, 330-714, Korea

E-mail: jcahn@dankook.ac.kr irradation of a specific wavelength. Because of this selective accumulation, only cancer cells are killed without causing any harm to the normal tissue. Thus PDT, a localized cancer treatment method that can remove specific malignant cells, has been increasingly recognized as a promising therapeutic method for a wide range of cancers, such as cervical cancer and head and neck cancer (Hampton and Selman 1992; Hopper 2000; Yamaguchi et al. 2005; Copper et al. 2007). The intracellular mechanism of action of PDT is a physical phenomena in which, the light of a specific wavelength activates the photosensitizer from the ground state to singlet state or a triplet state and the photosensitizer returns to the ground state by emitting energy to generate reactive oxygen species (ROS) by the reaction with oxygen (Type II reaction) or sensitization involved in the electron transport chain for free radical formation and thus destroy the cancer cells (Type I reaction) (Foote 
1987; Moan and Berg 1991; Ochsner 1997). Therefore, PDT can leads to apoptosis of cancer cell by the release of mitochondrial cytochrome c into the cytosol (Buytaert et al. 2007) and thus results in chromatin condensation, cleavage of chromosomal DNA into internucleosomal fragments, cell shrinkage, membrane blebbing, and the formation of apoptotic bodies without plasma membrane breakdown (Buytaert et al 2007). A new photosensitizer, 9-Hydroxypheophorbide-a (9-HpbD-a) has been developed from hematophorphyrin derivative $(\mathrm{HpD})$ and several reports have published showing its effecacy and applicability used in partial remission or actual clinical complete remission (Dahle et al. 1999). On the other hand, photosensitizer like $\mathrm{HpD}$ has also been reported that tumor vascular damage indirectly may also cause cell necrosis (Gomer et al. 1989). Therefore this new photosensitizer $9-\mathrm{HpbD}$-a may be a promising option for PDT.

In the present study, the antitumor effect of $9-\mathrm{HpbD}-\mathrm{a}$ mediated PDT has been studied and the mechanism of the action was investigated. Photosensitizer 9-HpbD-a was extracted from green alga Spirulina platensis and treated against human squamous cell carcinoma $\mathrm{HN} 3$ cells. Several parameters have been studied to test its efficacy of PDT in vitro. Western blot analysis was done to check the related apoptosis pathways. The efficacy of this newly developed photosensitizer was also tested in vivo. PDT with 9-HpbD-a was found to induce apoptosis in $\mathrm{HN} 3$ cells and was also found to be effective in reducing tumor in mice. Thus this study can lead to a higher efficacy of PDT with the newly developed photosensitizer 9-HpbD-a. Though more pre-

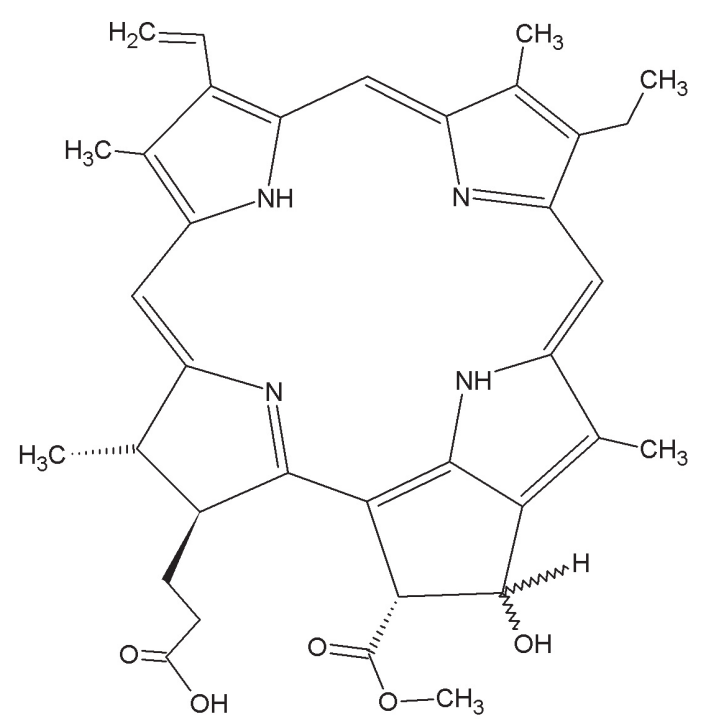

Figure 1. Chemical structures of 9-hydroxypheophorbide-a (9HpbD-a). Molecular formula: $\mathrm{C}_{35} \mathrm{H}_{38} \mathrm{~N}_{4} \mathrm{O}_{5}$; molecular weight: 617.2764. clinical and clinical studies are required for the further development of the proposed method, this new sensitizer can be a promising option for PDT. Therefore this study may explore a new avenue in the field of cancer treatment by PDT.

\section{Materials and Methods}

\section{Chemicals and antibodies}

All medium and supplements for cell culture like RPMI, fetal bovine serum (FBS) and antibiotics were supplied by Hyclone (South Logan, UT, USA). 3-[4,5-dimethylthiazol2-yl]-2,5-diphenyl-tetrazolium bromide (MTT), dimethyl sulfoxide (DMSO), Hoechst(33342), propidium iodide (PI), RIPA buffer, protease and phosphatase inhibitors were purchased from Sigma (Saint Louis, MO, USA). Bradford Reagent was supplied by Bio-Rad (Hercules, CA, USA). Cytochrome c, caspase 3, caspase 8, caspase 9 , caspase 12 and GAPDH were purchased from Calbiochem (Darm Stadt, Germany), SantaCruz (CA, USA) and Abcam (Cambridge, $\mathrm{UK})$, respectively.

\section{Preparation of photosensitizer}

The photosensitizer was developed in Kumho Life and Environmental Science Laboratory (Kwangju, Korea) and Dankook medical laser center (Cheonan, Korea) from chlorophyll of algae by oxidation and acid treatment with the 10-hydroxypheophytin. A derivative photosensitizer extracted using an organic solvent, 10-hydroxypheophytin in the process of organic synthesis. After stable structure and mass and 9-HpbD-a red yielded and 9-HpbD-a were used for further study (Figure 1).

\section{Cell Culture}

Human squamous cell carcinoma cell line HN3 was established form the head and neck cancer patients from Asan Medical Center. HN3 cells were cultured and maintained in RPMI-1640 (GibcoBRL, USA) culture medium containing 10\% FBS (GibcoBRL, USA) and antibiotic-antimycotic solution (Gibco BRL) in an incubator maintaining $5 \% \mathrm{CO}_{2}$ and temperature of $37^{\circ} \mathrm{C}$ (Thermo Forma, USA). Morphology of the cells was observed through an inverted microscope (Olympus CK40, Japan).

\section{Morphological study}

HN3 cells cultured in the exponential growth phase, diluted to a concentration of $10^{5}$ cells $/ \mathrm{ml}$ were seeded onto a 96 well plate and maintained $37^{\circ} \mathrm{C}, 5 \% \mathrm{CO}_{2}$ environment for 
24 hours. The sensitizer 9-HpbD-a was diluted in DPBS and was added cell culture medium at different concentrations from $0-10 \mu \mathrm{g} / \mathrm{ml}$. After 6 hours, cells were irradiated with diode laser of $670 \mathrm{~nm}, 0.5 \mathrm{~W}$ for $15 \mathrm{~min}\left(3.2 \mathrm{~J} / \mathrm{cm}^{2}\right)$. Cells were then observed under microscope (Olympus, CK40, Japan) and the photographs were taken.

\section{Cytotoxicity measurement}

MTT assay was performed to evaluate the activity of PDT by photosensitizer and laser irradiation on cell toxicity (Scudiero et al. 1988). 6 hours after the laser irradiation, $50 \mu \mathrm{l}$ of MTT solution ( $2 \mathrm{mg} / \mathrm{ml}$, Sigma) was added to the each well. The cells were then incubated at $37^{\circ} \mathrm{C}$ and $5 \% \mathrm{CO}_{2}$ for 4 hours. After the incubation, the medium of the each well was removed and formazan was dissolved with $150 \mu \mathrm{l}$ dimethylsulfoxide (DMSO: KANTO, Japan) followed by mixing by microplate mixer (Amersham, UK). The absorbance of each well was measured at $540 \mathrm{~nm}$ by microplate reader (BIO-RAD 550, USA). Percentage of cell viability was calculated using the following equation for each concentration of the photosensitizer and the results were obtained by mean absorbance.

$$
\text { Cell viability }(\%)=\frac{\text { Mean optical density in test well }}{\text { Mean optical density in control well }} \times 100
$$

\section{Apoptotic and necrotic cells staining}

Two types of fluorescent dyes Hoechst 33342 (Sigma, USA) and PI (Sigma, USA) were used to determine the mechanism of cell death caused by PDT. The nuclei of apoptotic cells and normal cells were stained blue with Hoechst 33342 (Sigma, USA) and the nucleus of necrotic cells were stained red with PI (Crissman, 1995). Cells were treated with 9-HpbD-a followed by the laser irradiation. After 6 hours of incubation Hoechst and PI solution ( $5 \mu \mathrm{g} / \mathrm{ml}$, Sigma) were added to each well and the cells were observed using a fluorescence microscope (Olympus, Japan).

\section{Western blot analysis}

Cells were treated with $0.29 \mu \mathrm{g} / \mathrm{ml}$ of $9-\mathrm{HpbD}-\mathrm{a}$ and irradiated with laser of $670 \mathrm{~nm}$ as described before. Cells were harvested after $0,3,6,9,12$ hours of laser irradiation. After treatment, the cells were washed with cold DPBS twice and then the proteins were extracted in RIPA buffer. Concentrations of proteins were determined using Bradford dye reagent. Equivalent amounts of proteins were loaded onto $10 \%$ polyacrylamide gels, subjected to electrophoresis, and transferred to PVDF membrane. Electrophoresis and blotting were both performed using the PowerPac200 electrophoresis system (Bio-Rad, Hercules). After blocking with 5\% non-skimmed milk for $1 \mathrm{~h}$, the membrane was incubated overnight at $4^{\circ} \mathrm{C}$ in primary antibodies. The membranes were probed with horseradish peroxidase-conjugated antimouse IgG or anti-rabbit IgG antibody for $1 \mathrm{~h}$. The protein band was detected by Kodak in vivo image analyzer (Kodak in Vivo Fx).

\section{Transmission electron microscopy (TEM)}

HN3 cells were detached from the culture flask after $6 \mathrm{~h}$ of incubation after treatment and washed twice with DPBS (Hyclone, USA). Cells were then fixed in $4 \%$ formaldehyde and $1 \%$ glutaraldehyde in $0.1 \mathrm{M}$ PBS ( $\mathrm{pH} 7.4$ ) by mixing equal volume of fixative and cell suspension followed by post fixation with $1 \mathrm{ml}$ of $1 \% \mathrm{OsO}_{4}$ solution dissolved in phosphate buffer. Cells were then washed twice with PBS and dehydrated with 50\% , 70\%, 95\%, 100\% ethanol and $100 \%$ propylene oxide $15 \mathrm{~min}$ each and the cells were observed by adding staining after infiltration, embedding and block trimming in semi-thin section and thin section.

\section{The PDT of xenograft tumors}

$\mathrm{HN} 3$ cell were maintained in monolayer culture at $37^{\circ} \mathrm{C}$ and $5 \% \mathrm{CO}_{2}$ incubator. Cells were then trypsinised and washed with DPBS and diluted to a concentration of $10^{8}$ cells $/ \mathrm{ml} .100 \mu \mathrm{l}$ of cell suspension were injected subcutaneously into the backs of nude mice. One week after the injection, formation of tumor was observed and the tumor volume was measured. All procedures in this study were carried out in accordance with the code of practice for the care and use of animals for scientific purposes approved by animal ethics committee, Dankook University School of Medicine.

When the tumor size reaches $400 \sim 600 \mathrm{~mm}^{3}$ in nude mice, $100 \mu \mathrm{l}$ of $9-\mathrm{HpbD}$-a, diluted in DPBS $(9.38 \mu \mathrm{g} / \mathrm{ml})$, was injected into the tumors evenly followed by the laser treatment with $0.96 \mathrm{~J} / \mathrm{mm}^{3}$ (400 $\mathrm{mW}$ ) of energy for 10-minute after $6 \mathrm{~h}$. Temperature changes by laser irradiation within the tumor were recorded.

\section{Measurement of tumor volume}

Tumor volume of mice in each group was measured after 1 , 2 , and 3 weeks of treatment (mean \pm standard deviation). Anti-tumor effect was evaluated at $4^{\text {th }}$ week. The tumor volume was calculated using the following formula:

$$
\mathrm{V}=(4 / 3 \times \mathrm{A} \times \mathrm{B} \times \mathrm{C}) \times 1 / 2
$$

where $\mathrm{V}$ is volume, $\mathrm{A}$ is major axis (length), $\mathrm{B}$ is shortening (width) and $\mathrm{C}$ is height. 

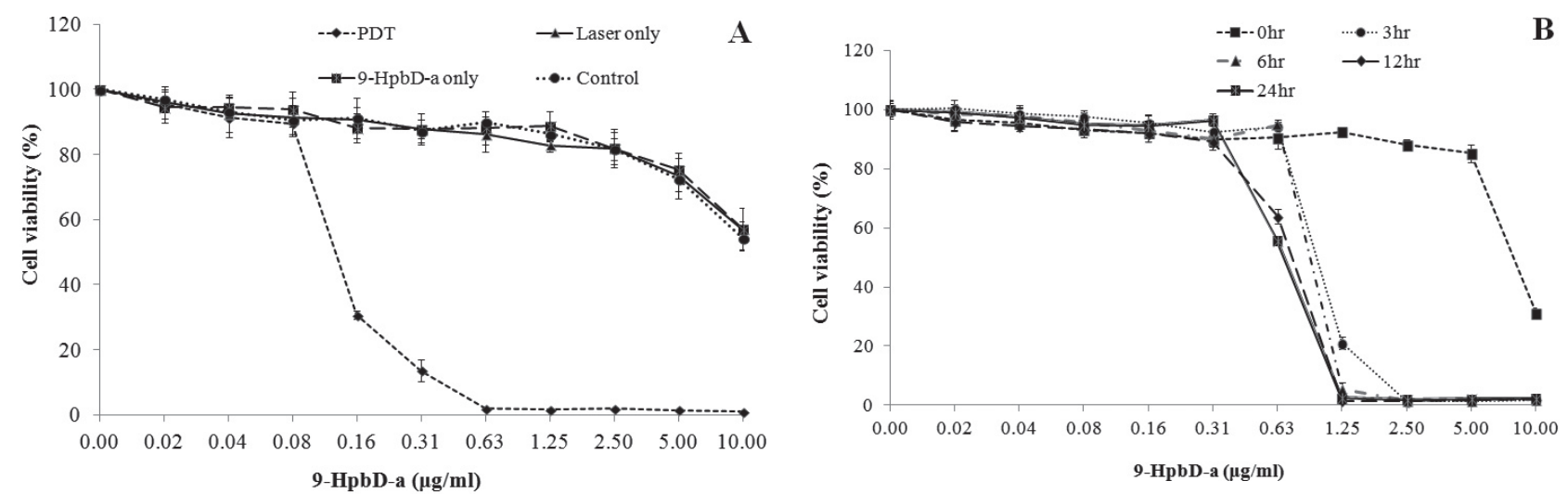

Figure 2. A. MTT assay showing the effect of laser, 9-HpbD-a and PDT compared to the control cells. B. Effect of various concentrations of 9-HpbD-a on cell viability upon irradiation for $0,3,6,9$ and $12 \mathrm{~h} .10^{4}$ cells per well were incubated for $6 \mathrm{~h}$ in presence of different amount of 9-HpbD-a. Control group were received no treatment.
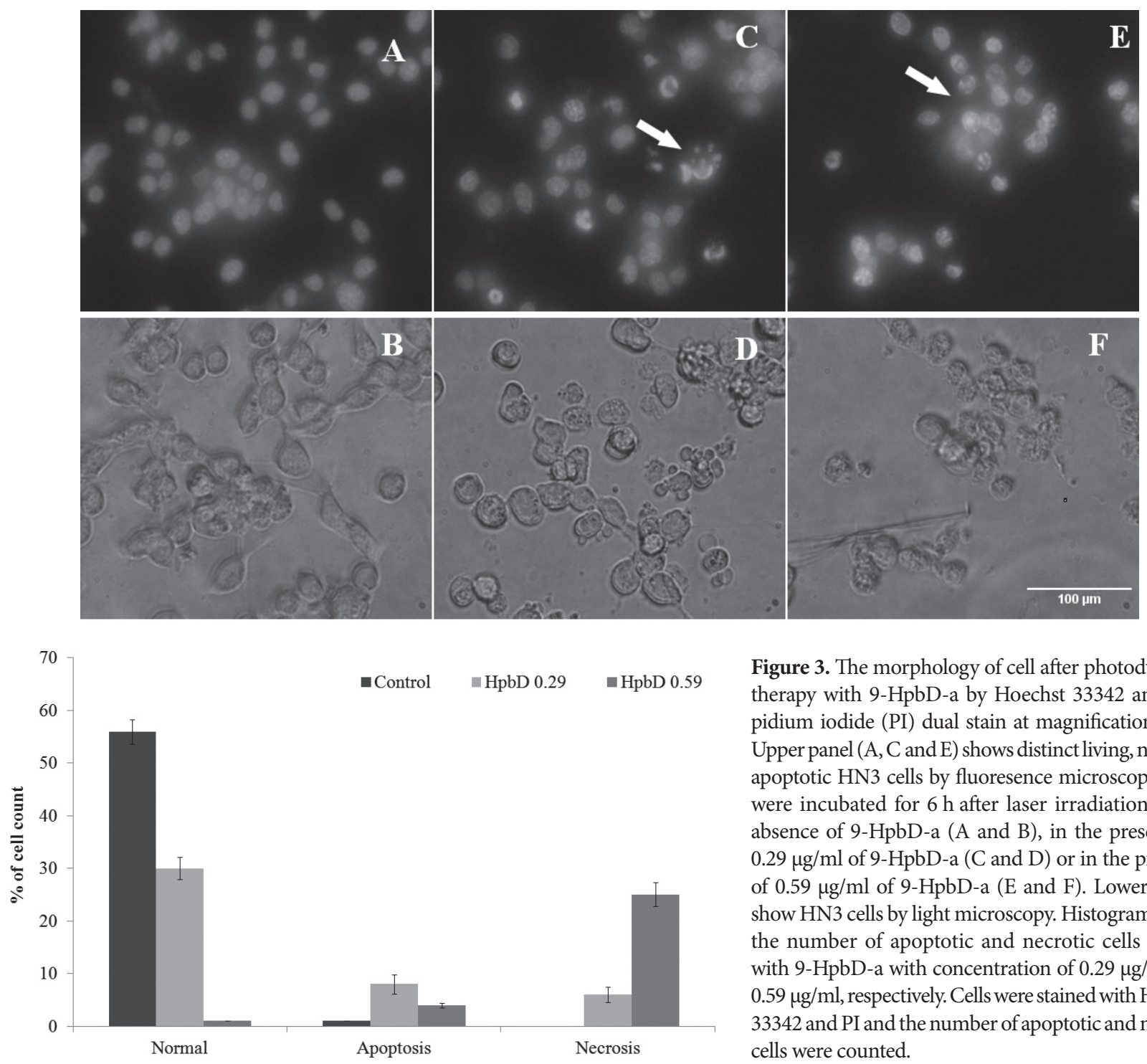

Figure 3. The morphology of cell after photodynamic therapy with 9-HpbD-a by Hoechst 33342 and propidium iodide (PI) dual stain at magnification $\times 200$. Upper panel (A, C and E) shows distinct living, necrotic, apoptotic HN3 cells by fluoresence microscopy. Cells were incubated for $6 \mathrm{~h}$ after laser irradiation in the absence of 9-HpbD-a (A and B), in the presence of $0.29 \mu \mathrm{g} / \mathrm{ml}$ of $9-\mathrm{HpbD}-\mathrm{a}(\mathrm{C}$ and $\mathrm{D})$ or in the presence of $0.59 \mu \mathrm{g} / \mathrm{ml}$ of $9-\mathrm{HpbD}-\mathrm{a}(\mathrm{E}$ and $\mathrm{F})$. Lower panels show $\mathrm{HN} 3$ cells by light microscopy. Histogram shows the number of apoptotic and necrotic cells treated with $9-\mathrm{HpbD}$-a with concentration of $0.29 \mu \mathrm{g} / \mathrm{ml}$ and $0.59 \mu \mathrm{g} / \mathrm{ml}$, respectively. Cells were stained with Hoechst 33342 and PI and the number of apoptotic and necrotic cells were counted. 


\section{Statistical analysis}

Antitumor effects of 9-HpbD-a tumors xenograft was analyzed using the SAS statistical program. The results from different time interval and concentration were analyzed by two-way ANOVA test and Student's $t$-test at the 95\% significance level.

\section{Results}

\section{Cytotoxicity assay}

Cell cytotoxicity was determined after administration of 9$\mathrm{HpbD}$-a for different time of laser irradiation. Cells were treated with different concentrations of 9-HpbD-a from 0-10 $\mu \mathrm{g} / \mathrm{ml}$ and different time interval from $0-12 \mathrm{~h}$ after laser irradiation. As is seen on Figure 2, there were no such change in cell viability for laser or 9-HpbD-a only treated groups (Figure 2A) but percentages of dead cell for PDT at 9-HpbD-a concentration of 0.29 $\mu \mathrm{g} / \mathrm{ml}$ were $89.80 \%, 92.48 \%, 90.14 \%, 92.56 \%$ and $89.27 \%$ for 0 , $3,6,9,12$ hours incubation after laser irradiation, respectively (Figure 2B). The percentages of cell death were increasing significantly at $0.59 \mu \mathrm{g} / \mathrm{ml}$ of $9-\mathrm{HpbD}-\mathrm{a}: 90.60 \%, 94.30 \%, 94.69 \%$, $55.72 \%$ and $63.95 \%$ for the incubation time of $0,3,6,9,12$ hours, respectively. Thus, the cell viability of $\mathrm{HN} 3$ cells was decreased with the increasing concentrations of $9-\mathrm{HpbD}$-a as well as with the increasing incubation time (Figure 2B).

\section{Apoptosis analysis}

\section{Apoptotic cells and necrotic cells staining}

To distinguish the apoptotic and necrotic cells during PDT, Hoechst 33342 and PI staining was performed. Apoptotic cells were observed as bright blue stained cells with round shaped morphology and apoptotic bodies. Red round nuclei represent the necrotic cells under fluorescence microscopy (UV filter 330-385 nm) (Figure 3A, C and E). The morphology of the cell was also observed. The cell morphology was changed and apoptotic bodies were observed in the treated cells (Figure 3B, D and F). At a concentration of $0.29 \mu \mathrm{g} / \mathrm{ml}$ of $9-\mathrm{HpbD}-\mathrm{a}$, the percentage of apoptotic cell was higher than that of necrotic cells which primarily confirmed the cell death mechanism by apoptosis. But at a concentration of $0.59 \mu \mathrm{g} / \mathrm{ml}$ of $9-\mathrm{HpbD}-\mathrm{a}$, the percentage of apoptotic cell was lesser than that of necrotic cells that indicates the increase of necrosis with concentration of 9-HpbD-a (Figure 3B).

\section{Western blot analysis}

$\mathrm{HN} 3$ cells were treated with $9-\mathrm{HpbD}$-a at a concentration of $0.29 \mu \mathrm{g} / \mathrm{ml}$ followed by the laser irradiation at $670 \mathrm{~nm}$.
The expressions of different proteins related to apoptosis were studied after different time interval after laser irradiation. The expressions of mitochondrial pathway related protein cytochrome c, caspase 9, caspase 3 and PARP were upreglated. Caspase 12 as well as caspase 8 was expressed in the PDT-treated cells (Figure 4). The expressions of the cytochrome c, caspase 9 and caspase 3 were increased very high at $3 \mathrm{~h}$ of time interval. On the other hand, caspase- 8 and caspase- 12 were also expressed after $12 \mathrm{~h}$ of incubation.

\section{Transmission electron microscopy (TEM)}

Under transmission electron microscopy (TEM), at $0.29 \mu \mathrm{g} /$ $\mathrm{ml}$ of $9-\mathrm{HpbD}-\mathrm{a}$, chromatin enrichment of apoptotic cells was observed and the overall size of the cells were found to be decreased. The size of the nucleus was smaller than in the nucleus of normal cells. At a concentration of $0.59 \mu \mathrm{g} / \mathrm{ml}$ of 9-HpbD-a the cell membrane is damaged for the necrotic cells (Figure 5).

\section{The photodynamic therapy of xenograft tumors}

Nude mouse were injected with head and neck carcinoma cell lines at a concentration of $10^{8}$ cells/ $100 \mu \mathrm{l}$ and the formation of tumors were observed and the tumor volumes were measured at 1-week interval. After 1 week tumors of nude mouse were formed of $34.3 \pm 24.2 \mathrm{~mm}^{3}$. The sizes of the

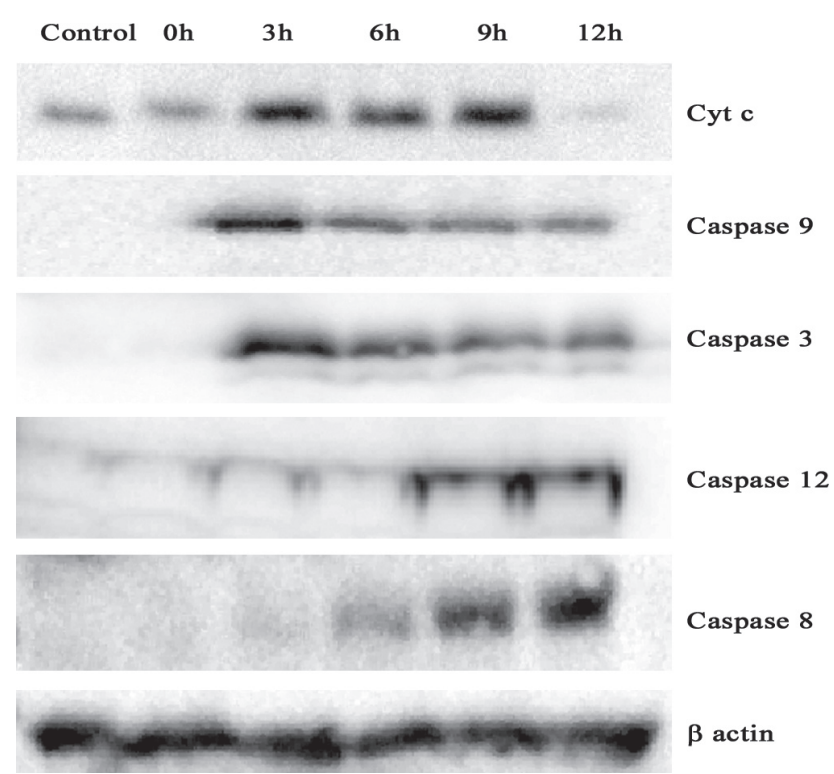

Figure 4. Western blot analysis of different proteins in different apoptotic pathways. Cells were harvested and the proteins were collected at different time interval after laser irradiation. 

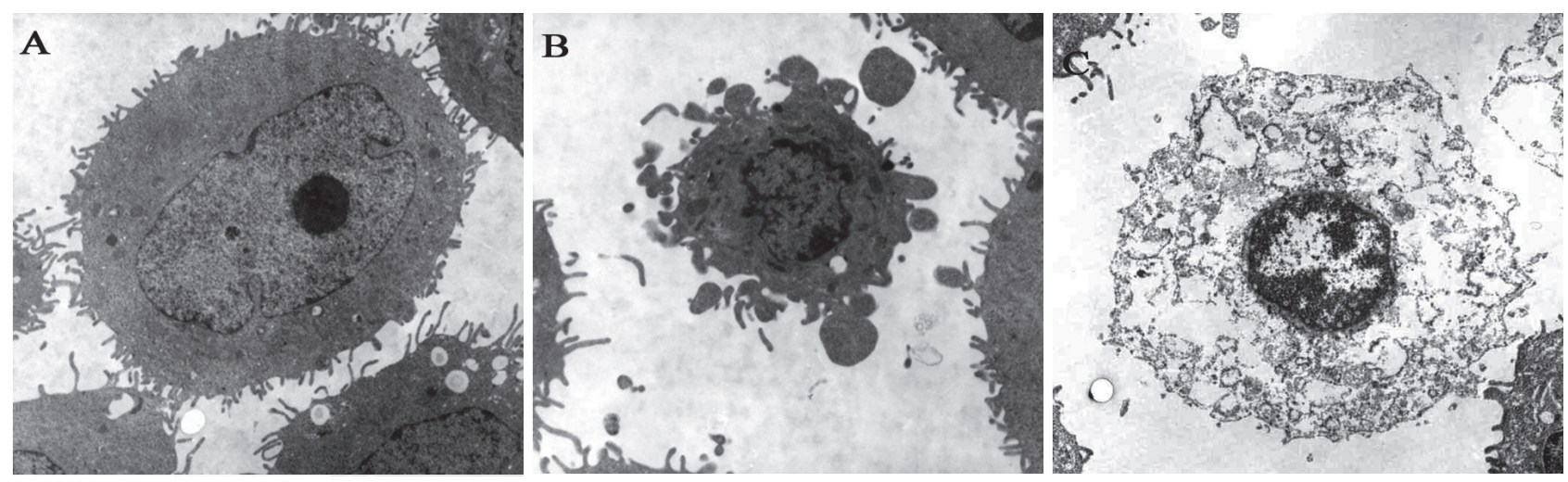

Figure 5. Electron micrographs of HN3 cells 6 h after laser irradiation. A. Normal untreated cell (magnification $\times 8000)$. B. The cell with apoptotic nuclei (magnification $\times 9000)$. C. A necrotic cell with shrinkage and cytoplasmic membrane disruption (magnification $\times 8000)$.

tumor after 2,3 and 4 weeks were $82.9 \pm 40.1,71.1 \pm 67.9$ and $352.9 \pm 126.8 \mathrm{~mm}^{3}$, respectively.

Tumor volume of mice from different groups was observed. For normal control group and 9-HpbD-a treated group a continuous growth of tumor were observed. However, for laser treated group, one recurrence out of four was found and interestingly for the PDT-treated group, ten out of sixteen were found to have complete remissions (Figure 6). The changes in tumor volume for control, 9-HpbD-a treated, laser-treated and PDT-treated group were shown in Figure 7.
Up to 4 weeks, tumor volume of all group was increased before treatment (Figure 7A). For the control and 9-HpbD-a treated tumor volume did not reduced up to 4 weeks of treatment (Figure 7B, C), for laser-treated group some tumors in the mice were found to be reduced (Figure 7D) but for PDTtreated group most of the mice were found to have reduced size in tumor (Figure 7E). Table 1 shows the percentages of no remission, recurrence and complete remission of control and different treated groups. PDT with 9-HpbD-a groups shows approximately $62.5 \%$ complete remission.
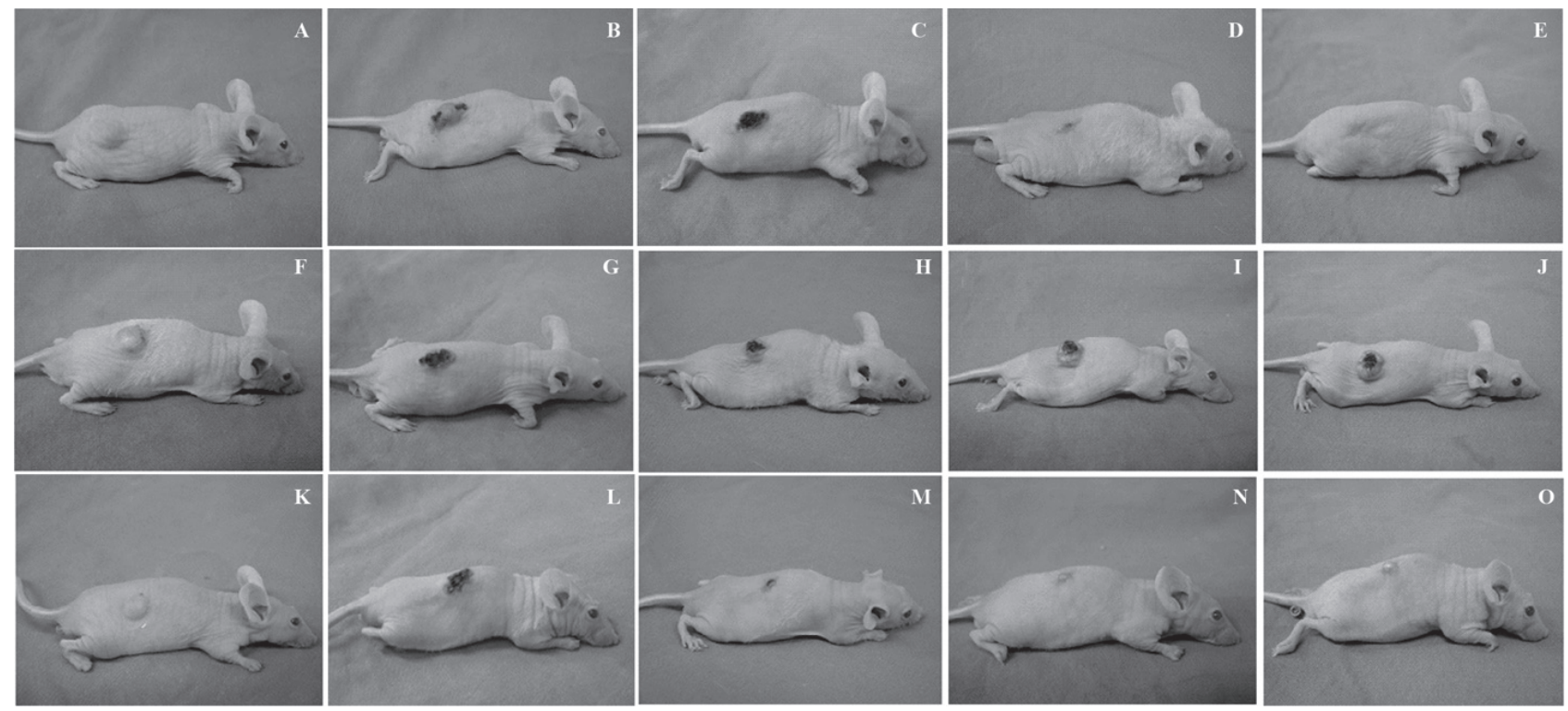

Figure 6. Complete tumor remission after PDT. Tumor appearance before PDT (A), immedately after laser irradiation (B), 1 week (C), and 2 weeks (D) after PDT. Follow-up at 4 weeks shows complete tumor remission (E). F-J show same time interval of the mice treated with laser only. (K-O) shows tumor recurrence after PDT. Tumor appearance before (K) PDT, 1 week (L), 2 weeks (M) and 3 weeks (N) after PDT. Follow-up at 4 weeks shows recurrence $(\mathrm{O})$. 
A

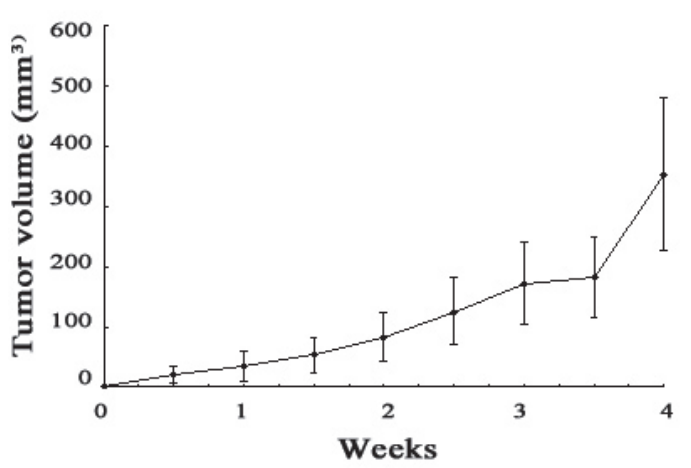

C

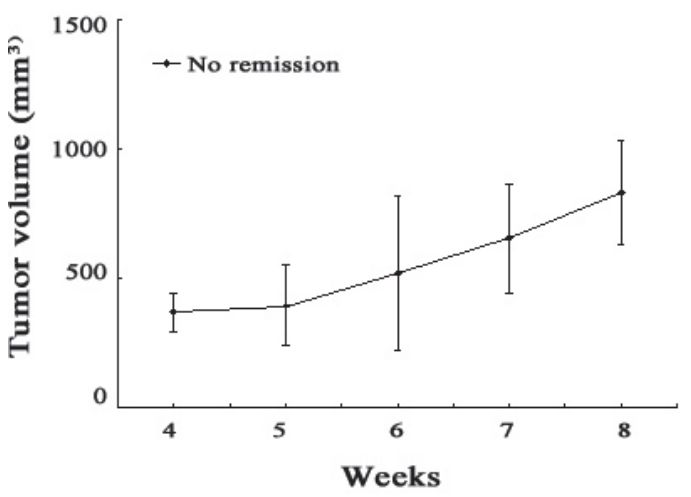

B

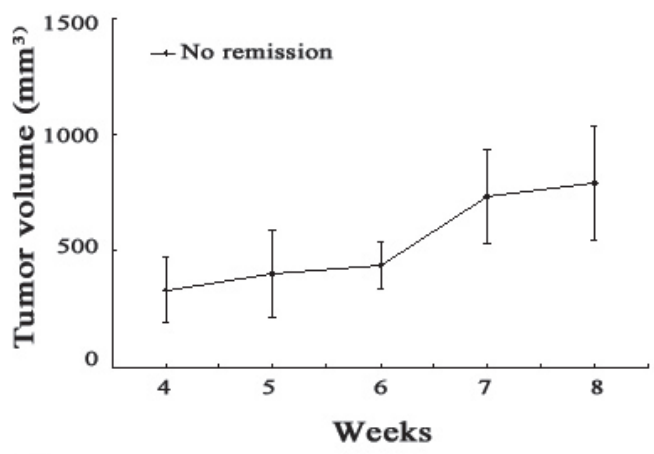

D

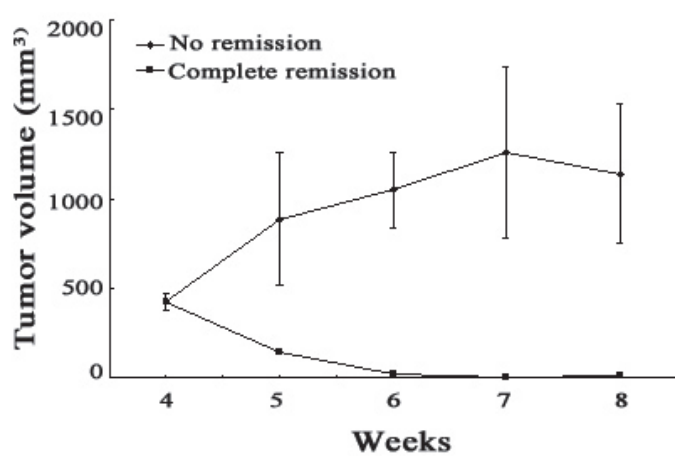

$\mathbf{E}$

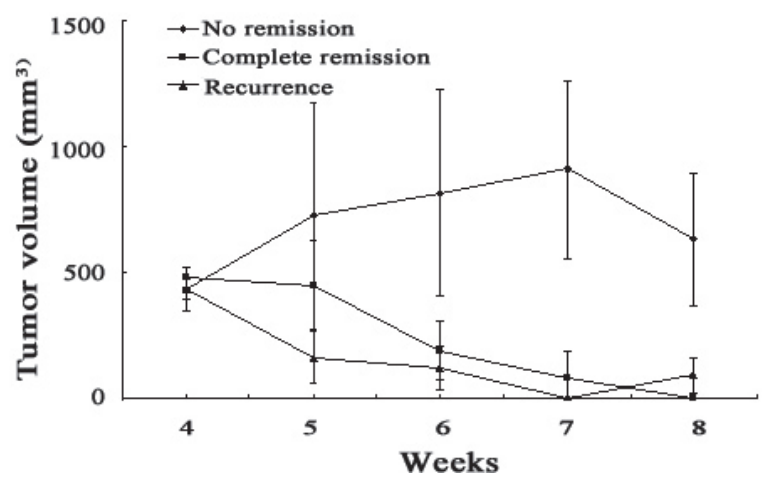

Figure 7. Growth curve of xenografted tumor in nude mouse (A). Tumor volume change of xenografted HN3 cells in normal control group (B), 9-HpbD-a only group (C), laser irradiation only group (D), PDT-treated group (E). Laser irradiation only group (D) showed 1 recurrence out of 4, and PDT-treated group (E) showed 10 complete remission, 4 recurrence and 2 no remission out of 16 . Group IV showed significant remission rate, comparing to other groups.

Table 1. Results of photodynamic therapy on xenografted nude mouse showing no remission, recurrence and complete remission of tumor from different treated groups

\begin{tabular}{lcccc}
\hline Group & No remission (\%) & Recurrence (\%) & Complete remission (\%) & $\mathrm{n}$ \\
\hline Normal control & $4(100)$ & - & - & 4 \\
9-HppbD-a & $4(100)$ & - & - & 4 \\
Laser irradiation & $3(75)$ & $1(25)$ & - & 4 \\
9-HppbD-a + laser & $2(12.5)$ & $4(25)$ & $10(62.5)$ & 16 \\
\hline
\end{tabular}




\section{Discussion}

In order to perform PDT, light of a specific wavelength and a photosensitizer that can be activated by the light are mainly used. Diode laser used in this study can be suitable for the maximum of the absorption spectrum of the newly developed photosensitizer. PDT must provide an enhanced therapeutic response to be used as a first-line curative modality (Gomer et al 2006). There may be some differences in the cytotoxicity of the laser used in the treatment depending on how the light for a short period of time can cause damage to the tumor cells without causing any damage to the adjacent normal cells (Muller et al. 1998).

A new photosensitizer, 9-HpbD-a was developed from the chlorophyll a of green alga Spirulina platensis. It is a hematophorphyrin derivative (HpD) which has the advantage of being able to prevent the accumulation in the body for a long time to reduce the side effects. In addition, 9-HpbD-a has maximum absorption wavelength at $665 \mathrm{~nm}$. Therefore higher wavelengths in the visible region increase the efficacy of penetration depth to increase the effectiveness of PDT. Laser of higher permeability within the tumor enhances the therapeutic effects of photosensitizer.

In the present study we evaluated the efficacy of newly developed photosensitizer 9-HpbD-a against human head and neck cancer cell HN3. We also performed a xenograft protocol using human head and neck cancer cell HN3 in nude mice. To evaluate the efficacy of PDT with the new photosensitizer in vitro, different parameter like cytotoxicity assay, Hoechst/PI staining, Western blot analysis was performed. The efficacy of PDT was also tested in vivo xenograph model. The percentage of cell viability was decreased with the increasing concentration of 9-HpbD-a. The cytotoxicity of PDT also increased with the time of incubation after laser irradiation. In Hoechst/PI staining, the percentage of apoptotic cells is higher in the lower concentration of $9-\mathrm{HpbD}$-a whereas the necrotic cell number was increased in the higher dose of photosensitizer. In the Western blot analysis, the expressions of different proteins related to apoptosis were modified. The expressions of cytochrome c, caspase 9, caspase 3 and PARP were upreglated. Caspases play critical roles in the initiation and execution of apoptosis and are activated by cytochrome c (Budihardjo et al. 1999). This indicates apoptosis in HN3 cells may have undergone through mitochondrial pathways. Caspase 12 was also modified indicating the endoplasmic reticulum stress related pathways and the caspase 8 was expressed in the PDT-treated cells. The expressions of the cytochrome c, caspase 9 and caspase 3 were increased at $3 \mathrm{~h}$ of time interval and caspase 8 and caspase 12 were expressed high after 12 hours of incubation. Therefore mitochondrial pathways are activated first and then endoplasmic reticulum stress related pathways and the other pathways are activated with time to induce apoptosis in HN3 cells treated with 9-HpbD-a PDT. Again apoptosis was the main cell death factor when low concentration of 9-HpbD-a was used for PDT and a high concentration of $9-\mathrm{HpbD}$-a was identified as the main mechanism of cell death by necrosis. The same trends of results were observed under TEM study. The tumor volume in the xenograph mice was also reduced when the mice were treated with 9-HpbD-a mediated PDT. The tumor remission in the PDT treated group was more effective than that in laser treated group. The control and 9-HpbD-a treated group did not showed any remission of tumor. Therefore the newly developed photosensitizer 9-HpbD-a was found to be effective not only against head and neck cancer cell but also against in vivo tumor xenograph model.

Although PDT is an alternative method of treatment for cancer and many other diseases, a new photosensitizer with excellent good tissue penetration can lead to higher efficacy of PDT. To enhance our knowledge, it is necessary to have reliable preclinical models though the cell lines and mice xenograft models as described here can also put footstep for further clinical study. However, the higher efficacy of PDT with its reduced side effects in combination therapy, make it one of the most promising approaches for the development of new therapies for head and neck cancer and other types of cancer.

Acknowledgement. This research was supported by Leading Foreign Research Institute Recruitment Program through the National Research Foundation of Korea (NRF) funded by the Ministry of Education, Science and Technology (MEST) (2012K1A4A3053142).

The authors declare no conflict of interest.

\section{References}

Budihardjo I., Oliver H., Lutter M., Luo X., Wang X. (1999): Biochemical pathways of caspase activation during apoptosis. Annu. Rev. Cell. Dev. Biol. 15, 269-290

http://dx.doi.org/10.1146/annurev.cellbio.15.1.269

Buytaert E., Dewaele M., Agostinis P. (2007): Molecular effectors of multiple cell death pathways initiated by photodynamic therapy. Biochim. Biophys. Acta 1776, 86-107

Regillo C. D. (2000): Update on photodynamic therapy. Curr. Opin. Ophthalmol. 11, 166-170

http://dx.doi.org/10.1097/00055735-200006000-00002

Copper M. P., Triesscheijn M., Tan I. B., Ruevekamp M. C., Stewart F. A. (2007): Photodynamic therapy in the treatment of multiple primary tumours in the head and neck, located to the oral cavity and oropharynx. Clin. Otolaryngol. 32, 185-189 http://dx.doi.org/10.1111/j.1365-2273.2007.01441.x

Crissman, M. J. (1995): Cell cycle analysis by flow cytometry. In: Cell Growth and Apoptosis. (Ed. G. P. Studzinski), 2nd edition, pp. 21-43, IRL press, Oxford 
Dahle J., Steen H. B., Moan J. (1999): The mode of cell death induced by photodynamic treatment depends on cell density. Photochem. Photobiol. 70, 363-367 http://dx.doi.org/10.1111/j.1751-1097.1999.tb08150.x

Dougherty T. J., Kaufman J. E., Goldfarb A., Weishaupt K. R., Boyle D., Mittleman A. (1978): Photoradiation therapy for the treatment of malignant tumors. Cancer Res. 38, 2628-2635

Foote C. S. (1987): Type I and Type II mechanisms of photodynamic action. In: American Chemical Society. (Eds. J. R. Heitz and K. R Downum), American Chemical Society, pp. 22-28, Washington D.C.

Gomer C. J., Ferrario A., Luna M., Rucker N., Wong S. (2006): Photodynamic therapy: combined modality approaches targeting the tumor microenvironment. Lasers Surg. Med. 38, 516-521 http://dx.doi.org/10.1002/lsm.20339

Gomer C. J., Rucker N., Ferrario A., Wong S. (1989): Properties and applications of photodynamic therapy. Radiat. Res. 120, 1-18 http://dx.doi.org/10.2307/3577632

Hampton J. A., Selman S. H. (1992): Mechanism of cell killing in photodynamic therapy using a novel in vivo drug/in vitro light culture system. Photochem. Photobiol. 56, 235-243 http://dx.doi.org/10.1111/j.1751-1097.1992.tb02152.x

Hopper C. (2000): Photodynamic therapy: a clinical reality in the treatment of cancer. Lancet Oncol. 1, 212-219 http://dx.doi.org/10.1016/S1470-2045(00)00166-2
Moan J., Berg K. (1991): The photodegradation of porphrins in cells can be used to estimate the lifetime of singlet oxygen. Photochem. Photobiol. 53, 549-553 http://dx.doi.org/10.1111/j.1751-1097.1991.tb03669.x

Muller S., Walt H., Dobler-Girdziunaite D., Fiedler D., Haller U. (1998): Enhanced photodynamic effects using fractionated laser light. J. photochem. Photobiol. B 42, 67-70 http://dx.doi.org/10.1016/S1011-1344(97)00124-3

Ochsner M. (1997): Photophysical and photobiological processes in the photodynamic therapy of tumors. Photochem. Photobiol. 39, 1-18 http://dx.doi.org/10.1016/S1011-1344(96)07428-3

Scudiero D. A., Shoemaker R. H., Paull K. D., Monks A., Tierney S., Nofziger T. H., Currens M. J., Seniff D., Boyd M. R. (1988): Evaluation of a soluble tetrazolium/formazan assay for cell growth and drug sensitivity in culture using human and other tumor cell lines. Cancer Res. 48, 4827-4833

Yamaguchi S., Tsuda H., Takemori M., Nakata S., Nishimura S., Kawamura N., Hanioka K., Inoue T., Nishimura R. (2005): Photodynamic therapy for cervical intraepithelial neoplasia. Oncology 69, 110-116 http://dx.doi.org/10.1159/000087812

Received: September 17, 2012

Final version accepted: February 20, 2013 